\title{
KEPATUHAN MENGONTROL TEKANAN DARAH SEBAGAI UPAYA MENURUNKAN KEJADIAN INFARK MIOKARD AKUT RECURRENT
}

\author{
Abdul Qodir \\ Abdulqodir.ners@gmail.com \\ Prodi Ilmu Keperawatan \\ STIKES Widyagama Husada
}

\begin{abstract}
Recurrent of acute myocardial infarction especially accurring 1 year after the prior one. Patiens who has experience myocardial infarction had risk 50\% to recurrent. The aim of this study is to identify the relation of adherence to control blood pressure with recurrent of acute myocardial infarction occurance. Case control study design was used in this study. Samples were selected by consecutive sampling technique. The samples size were 90 patients consisted of 45 cases (recurrent) and 45 controls (no recurrent). Chi Square were used to examine the relation of adherence to control blood pressure with recurrent of myocardial infarction occurrence. The result showed that there was a significant corelation of adherence to control blood pressure $(p=0,000)$ with recurrent of acute myocardial infarction. It is concluded that there was a significant corelation between adherence to control blood pressure and recurrent of acute myocardial infarction.
\end{abstract}

Key words: Adherence, Blood pressure, Recurrent of Acute Myocardial Infarction 


\begin{abstract}
ABSTRAK
Infak miokard akut recurrent bayak terjadi terutama pada 1 tahun setelah serangan pertama. Pasien yang pernah mengalami serangan infark miokard akut 50\% kemungkinan akan mengalami infark miokard akut recurrent akibat pasien tidak patuh mengontrol faktor risiko. Tujuan penelitian ini adalah untuk mengetahui hubungan kepatuhan mengontrol faktor risiko dengan kejadian infark miokard akut recurrent. Penelitian dilakukan dengan mengunakan desain case control. Teknik pengambilan sampel yaitu consecutive sampling. Jumlah sampel penelitian 90 pasien infark miokard akut yang terdiri dari 45 pasien kasus (recurrent) dan 45 pasien kontrol (tidak recurrent). Analisis statistik yang digunakan adalah uji Chi Square. Hasil penelitian menunjukan bahwa terdapat hubungan yang signifikan antara kepatuhan mengontrol tekanan darah $(\mathrm{p}=0,000)$ terhadap kejadian infark miokard akut recurrent. Kesimpulan penelitian ini adalah terdapat hubungan yang signifikan antara kepatuhan mengontrol tekanan darah dengan kejadian infark miokard akut recurrent.
\end{abstract}

\title{
Kata Kunci : Kepatuhan, Tekanan darah, Infark Miokard Akut Recurrent
}

\section{PENDAHULUAN}

Penyakit jantung koroner merupakan masalah kesehatan diseluruh dunia Di Amerika angka kejadian penyakit jantung koroner 1 juta/tahun, sedangkan terdapat warga Amerika yang mengalami infark miokard akut setiap 29 detik dan meningal setiap menitnya (Topol EJ, 2009). Di Indonesia, penyakit jantung koroner cenderung meningkat dari tahun ketahun sebagai penyebab kematian.

Pada umumnya Infark Miokard Acut (IMA) dapat terjadi berulang, infark miokard berulang ini disebut dengan infark miokard akut recurrent karena faktor risiko yang tidak terkontrol atau ketidakpatuhan penderita dalam menjalani terapi rehabilitasi. Penderita yang pernah mengalami serangan sindrom koroner akut $50 \%$ kemungkinan akan mengalami recurrent. Pada tahun 2009 kurang lebih 785.000 warga Amerika mengalami serangan sindrom koroner akut dan lebih dari separuhnya atau 470.000 mengalami recurrent Lloyd JD et al., (2009 dalam Wainer \& Rabbani, 2010).

Infark miokard akut recurrent dapat dicegah dengan cara mengendalikan faktor risiko. Beberapa penelitian menjelaskan bahwa dengan pencegahan sekunder termasuk pengendalian faktor risiko dan pengobatan farmakologis dapat mencegah kejadian infark miokard akut recurrent dan menurunkan angka mortalitas dan morbiditas penderita coronary heart disease (Clark et al., 2005).

Pencegahan sekunder dengan mengendalikan salah satunya dengan mengontrol tekanan darah. Pencegahan sekunder tersebut berdasarkan bukti klinis dan penelitian yang menggunakan kontrol, sampel dalam jumlah yang besar (Antman et al., 2008; Smith et al., 2006).

Hipertensi merupakan faktor mayor terjadinya infak miokard akut. Makin tinggi tekanan darah makin tinggi kemungkinan terjadinya infark miokard akut. Tekanan darah yang meningkat secara perlahan merusak dinding pembuluh darah dengan memperkeras arteri dan mendorong terbentuknya bekuan darah dan aneurisme, yang semuanya mengarah pada infark miokard akut.

Hipertensi merupakan faktor tunggal yang berkaitan dengan kejadian recurrent dan angka kematian pada penderita infak miokard akut. Berdasarkan penelitian yang telah dilakukan oleh Sesso, 
et al (2004) menunjukan bahwa pasien yang sudah terdiagnosa coronary heart disease peningkatan tekanan darah berbanding lurus dengan terjadi peningkatan risiko untuk mengalami recurrent.

Pencegahan sekunder diperlukan untuk mengontrol hipertensi sehingga menurunkan kejadian infark miokard acut recurrent yang berdapak pada komplikasi yang lebih parah dan menurunkan angka kematian (Antman et al., 2008).

Angka ketidakpatuhan

melaksanakan terapi sangat rendah diantara pasien yang pernah mengalami IMA (Law MR, et al., 2009; Glader EL, et al., 2010). Sebagai contoh terapi anti hipertensi sudah terbukti aman dan dapat menurunkan kejadian stroke sebesar 30\% dan menurunkan kejadian IMA sebesar 15\% (Law MR, et al., 2009), tetapi terdapat penelitian melaporkan bahwa sekitar 50\% sampai $80 \%$ pasien sudah mendapatkan terapi akan tetapi tidak patuh untuk menjalankannya (Cramer JA, et al., 2008). Menurut WHO, ketidakpatuhan menjalankan terapi menyebabkan gagal mengontrol tekanan darah. Gagal mengontrol tekanan darah menyebabkan peningkatan IMA recurrent, stroke, dan rawat inap ulang. Hal tersebut sejalan dengan penelitian yang telah dilakukan oleh Mazzaglia et al., (2009) dimana dengan patuh mengontrol tekanan darah akan menurunkan kejadian penyakit jantung termasuk mencegah IMA recurrent.

\section{TUJUAN}

Tujuan penelitian ini adalah untuk mengetahui kepatuhan mengontrol tekanan darah dengan kejadian infark miokard akut recurrent.

\section{METODE}

Penelitian ini dilakukan dengan mengunakan desain case control. Teknik pengambilan sampel dengan cara consecutive sampling. Jumlah sampel penelitian 90 pasien infark miokard akut yang terdiri dari 45 kelompok kasus (recurrent) dan 45 kelompok kontrol (tidak recurrent). Kepatuhan mengontrol Tekanan darah diukur secara retropektif selama 1 tahun. Alat ukur yang digunakan adalah Morisky Medication Adherence Scale (MMAS) yang telah diuji validitas dan reliabilitasnya. Analisis statistik yang digunakan adalah uji Chi Square.

\section{HASIL PENELITIAN}

Jumlah responden yang diperoleh adalah 90 pasien infark miokard akut terdiri yang terdiri dari 45 kelompok kasus (recurrent) dan 45 kelompok kontrol (tidak recurrent). Karakteristik responden meliputi usia $>45$ tahun, jenis kelamin laki-laki dan perempuan yang kontrol dipoli klinik jantung RSUD dr. Saiful Anwar Malang. 
Tabel 1

\begin{tabular}{|c|c|c|c|c|c|c|c|c|}
\hline \multirow{4}{*}{$\begin{array}{c}\text { Kepatuhan } \\
\text { Mengontrol } \\
\text { TD }\end{array}$} & \multicolumn{4}{|c|}{ Kejadian IMA } & \multirow{2}{*}{\multicolumn{2}{|c|}{ Total }} & \multirow{4}{*}{$\begin{array}{c}\text { OR } \\
(95 \% C I)\end{array}$} & \multirow{4}{*}{$\begin{array}{c}p \\
\text { Value }\end{array}$} \\
\hline & \multicolumn{4}{|c|}{ Recurrent } & & & & \\
\hline & \multicolumn{2}{|c|}{ Recurrent } & \multicolumn{2}{|c|}{$\begin{array}{c}\text { Tidak } \\
\text { Recurrent }\end{array}$} & & & & \\
\hline & $\mathbf{n}$ & $\%$ & $\mathbf{n}$ & $\%$ & $\mathbf{n}$ & $\%$ & & \\
\hline Tidak Patuh & 34 & 77,3 & 10 & 22,7 & 44 & 100 & & \\
\hline Patuh & 11 & 23,9 & 35 & 76,1 & 46 & 100 & 10,81 & 0,000 \\
\hline Jumlah & 45 & 50,0 & 45 & 50,0 & 90 & 100 & & \\
\hline
\end{tabular}

Tabel 1 merupakan hasil analisis hubungan kepatuhan mengontrol tekanan darah dengan kejadian IMA recurrent diperoleh 34 orang (77,3\%) yang tidak patuh mengalami IMA recurrent. Sedangkan diantara pasien yang patuh, ada 11 orang $(23,9 \%)$ mengalami IMA recurrent. Hasil uji statistik diperoleh nilai $p=0,000$ maka dapat disimpulkan ada hubungan yang signifikan antara kepatuhan mengontrol tekanan darah dengan kejadian IMA recurrent. Dari analisis diperoleh nilai Odd Ratio $(\mathrm{OR})=10,81$ artinya pasien yang tidak patuh mengontrol tekanan darah mempunyai peluang 10,81 kali untuk mengalami IMA recurrent.

\section{PEMBAHASAN}

Hasil analisis diketahui secara independen terdapat hubungan yang signifikan antara kepatuhan mengontrol tekanan darah dengan kejadian infark miokard akut recurrent $(\mathrm{p}=0,000)$ dan $\mathrm{OR}$ $=10,81$ dimana responden yang tidak patuh mempunyai risiko lebih tinggi 10,81 kali mengalami kejadian infark miokard akut recurrent.

Banyak penelitian melaporkan bahwa hipertensi mempunyai hubungan yang signifikan dengan kejadian infark miokard akut recurrent, gagal jantung, stoke dan kematian akibat kelainan sistem kardiovaskuler. Peningkatan angka kejadian infark miokard akut recurrent dan kematian mendadak pada pasien yang mempunyai riwayat hipertensi berhungan dengan beberapa faktor seperti kerusakan endothelium pembuluh darah, aterosklerosis, resistensi insulin, hipertropi ventrikel kiri dan aritmia ventrikel (Picariello, C , et al., 2011). Pada studi KAMIR $48 \%$ pasien infark miokard akut (STEMI) dengan riwayat hipertensi setelah dianalisis dengan multivariat hipertensi merupakan faktor risiko independen terhadap infark miokard akut recurrent dan kematian pada pasien tersebut. Pada studi GISSI-2, kejadian infark miokard akut recurrent, recurrent angina, dan ventricular failure sangat tinggi pada pasien dengan hipertensi dibandingkan dengan pasien yang memiliki tensi normal dimana kondisi tersebut menyebabkan kematian dirumah sakit dalam waktu 6 bulan.

Berdasarkan teori, hipertensi merupakan faktor risiko terjadinya penyakit jantung koroner. Menurut Sesso, et al., (2004) bahwa pasien yang sudah terdiagnosa penyakit jantung koroner peningkatan tekanan darah berbanding lurus dengan peningkatan risiko infark miokard akut recurrent. Setiap kenaikan tekanan darah sistolik $20 \mathrm{mmHg}$ dan takan darah diastolik 10 akan meningkatkan risiko infark miokard akut recurrent 2 kali lebih besar dibandingkan dengan pasien tensi normal (Lewington et al., 2002). Peningkatan tekanan darah akan memberikan beban kepada jantung sehingga menyebabkan hipertropi ventrikel. Tekanan darah yang tinggi dan 
menetap juga akan menimbulkan disfungsi endothelium, peningkatan permiabilitas enditelium, stress mekanikal, dan hipertropi ventrikel kiri yang menyebabkan plak rupture dan spasme pembuluh darah koroner sehingga menyebabkan ischemia otot jantung dan jika tidak sergera mendapatkan reperfusi akan berdampak pada infark miokard akaut recurrent (Picariello, C et al., 2001).

Mekanisme tersebut dapat dicegah agar tidak terjadi kerusakan lebih lanjut melalui pencegahan sekunder untuk mengontrol hipertensi sehingga menurunkan kejadian recurrent yang berdampak pada komplikasi yang lebih parah dan kematian. Joint National Committee 7 (JNC 7) dan American Heart Association (AHA) mengeluarkan panduan untuk pencegahan sekunder dimana pasien yang memiliki riwayat infark miokard akut harus patuh minum obat ACE inhibitor, $\beta$ blocker, dan jika perlu antagonist aldosteron untuk mencapai terget tekanan darah $<140 \mathrm{mmHg}$ atau $<130 / 80 \mathrm{mmHg}$ pada pasien dengan diabetes dan penyakit ginjal kronis. Jika tekanan darah lebih dari 20/10 $\mathrm{mmHg}$ dari traget, pertimbangkan pemberian terapi dengan 2 macam obat dan salah satunya harus thiazide (Antman et al., 2008). Hal ini sesuai dengan teori Betty Neuman (2001) bahwa jika pasien patuh mengontrol hipertensi dapat meningkatkan garis pertahanan normal (line of defence) dan garis pertahanan resisten (line of resistence) sehingga sistem klien stabil, harmony, wellness dan balance (tidak terjadi kegawatan).

Pada penelitian ini pasien sudah mendapatkan terapi anti hipertensi sesuai dengan standar yang ada akan tetapi masih banyak pasien yang mengalami recurrent. Berdasarkan informasi dari kuesioner penyebab ketidakpatuhan pasien mengontrol tekanan darah karena pengobatan hipertensi memembutuhkan waktu sangat lama bahkan seumur hidup. Hal ini sejalan dengan Ameronco P., et al (2009) bahwa penyebab ketidakpatuhan pasien mengontrol tekanan darah adalah karena proses pengobatan yang sangat lama dan pasien tidak tahu akibat jika tidak patuh mengkonsumsi obat hipertenisi.

\section{KETERBATASAN PENELITIAN}

Pada penelitian ini data penelitian secara retropektif dengan jumlah sampel 90 orang yang terdiri dari 45 orang infark miokard akut dan 45 orang infark miokard akut recurrent yang memungkinkan terjadinya sampel bias. Pada penelitian ini kriteria pengukuran kepatuhan mengontrol tekanan darah hanya pada terapi obat dan nilai tekanan darah. Meskipun peneliti sudah berusaha mengontrol faktor yang menyebabkan infark miokard akut recurrent melalui pemilihan sampel yang homogen tetapi tidak sepenuhnya dapat terkontrol dengan baik.

\section{KESIMPULAN}

Terdapat hubungan yang signifikan antara kepatuhan mengontrol tekanan darah terhadap kejadian infark miokard akut recurrent.

\section{SARAN}

Penulis menyarankan agar meneliti variabel atau faktor risiko yang berdampak pada kejadian infark miokard akut recurrent. 
DAFTAR PUSTAKA

Antman et al., (2004). ACC/AHA Guidelines for the Management of Patients With ST-Elevation Myocardial Infarction. Circulation. 2004;110:588-636.

Antman, Hand M, Paul W et al., (2008). 2007 Focused Update of the ACC/AHA 2004 Guidelines for the Management of Patients With ST-Elevation Myocardial Infarction : A Report of the American College of Cardiology/American Heart Association Task Force on Practice Guidelines: Developed in Collaboration With the Canadian Cardiovascular Society Endorsed by the American Academy of Family Physicians: 2007 Writing Group to Review New Evidence and Update the ACC/AHA 2004 Guidelines for the Management of Patients With ST-Elevation Myocardial Infarction, Writing on Behalf of the 2004 Writing Committee. Circulation. 2008;117:296-329.

Brown MT \& Bussell JK. (2011). Medication Adherence: WHO Cares?. Mayo Clin Proc.86(4):304-314.

Brown JPR, Clark AM, Dalal H, Welch K, Taylor RS. (2011) Patient education in the management of coronary heart disease (Review). The Cochrane Library. 12.

Clark, A.M., Hartling, L., Vandermeer, B., \& McAlister, F.A. (2005). Meta analysis: secondary prevention programs for patients with coronary artery disease. Annals of Internal Medicine, 143(9), 659-72.

Dochterman, J.M. \& Bulechek, G.M. (2004). Nursing Interventions Classification(NIC). Iowa: Mosby.
Glader EL, Sjölander M, Eriksson M, Lundberg M. (2010). Persistent use of secondary preventive drugs declines rapidly during the first 2 years after stroke. Stroke. 41(2):397-401.

Gordon K, Smith F, Dhillon S. (2007). Effective chronic disease management: patients' perspectives on medication-related problems. Patient Educ Couns. 65(3):407-415.

Hemmelgarn, B., Zarnke, K., Campbell, N., Feldman, R., McKay, D. McAlister, D., Khan, N.,...Padwal, R. (2004). The 2004 Canadian hypertension education program recommendations for the management of hypertension: part 1-blood pressure measurement, diagnosis and assessment of risk. Canadian Journal of Cardiology, 20(1), 31-40.

Hertz RP, Unger AN, Lustik MB (2005). Adherence with pharmacotherapy for type 2 diabetes: a retrospective cohort study of adults with employersponsored health insurance. Clin Ther 27(7):106473.

Ho PM, Magid DJ, Shetterly SM, et al., (2008). Medication nonadherence is associated with a broad range of adverse outcomes in patients with coronary artery disease. Am Heart J. 2008;155(4):772-779.

Jarrin, O. (2007). An Integral philosophy and definition of nursing.Journal of Integral Theory and Practice, 2(4), 79-101.

Law MR, Morris JK, Wald NJ. (2009). Use of blood pressure lowering drugs in the prevention of cardiovascular disease: meta-analysis of 147 randomised trials in the context of expectations from prospective 
epidemiological studies. $B M J$.

2009;338:b1665.

Morisky D.E et., (2009) Predictive Validity of A Medication Adherence Measure in an Outpatient Setting. $J$ Clin Hypertens (Greenwich). 10(5): 348-354.

Sakakura K, Kubo N, Ikeda, et al. (2009). Clinical feature of early recurrent myocardial infarction. Heart Vessels. 24:347-351 .

Weiner SD \& Rabbani LE. (2010). Secondary prevention strategies for coronary heart disease. $\mathrm{J}$ Thromb Thrombolysis.29:8-24 
JURNAL ILMIAH KESEHATAN MEDIAHUSADA | VOLUME 05/NOMOR 01/MARET 2016 